\title{
LE CENTRE FRANÇAIS DU LITTORAL
}

Après plus de dix huit années d'existence le Centre Français du Littoral n'a pas besoin de justifier sa mission; cependant, il nous est apparu opportun de profiter de ce numéro spécial de "PARALIA" pour rappeler brièvement les mobiles qui ont présidé à sa création et préciser les objectifs poursuivis.

\section{ORIGINES DU CENTRE FRANÇAIS DU LITTORAL}

Le Centre Français du Littoral est le fruit de la réflexion d'un groupe de personnes investies de responsabilités administratives ou scientifiques qui, à l'époque, avaient pris conscience de la désaffection des populations de l'intérieur pour les choses de la mer, de son environnement et de son exploitation.

En réalisant un Centre d'Expression Thématique elles ont voulu favoriser la concertation entre les diverses branches d'activités concernées et permettre le développement de recherches spécifiques directement appliquées aux techniques d'exploitation ou à la protection du milieu.

\section{SA FORME JURIDIQUE}

Le Centre Français du Littoral est une association sans but lucratif régie par la loi du 1er juillet 1901, comprenant :

- un conseil d'administration,

- un comité scientifique, technique, et de développement

- ainsi que des professionnels directement ou indirectement intéresssés aux problèmes de la mer et dũ lituoral.

\section{SES OBJECTIFS}

Les objectifs qui découlent de l'objet même du Centre Français du Littoral, tel qu'il est défini dans les statuts, peuvent se rassembler en quatre points :

1) Promouvoir des études et des recherches scientifiques ou techniques dans les domaines:

- de la protection du site marin,

- de l'aménagement du littoral, 
- de la surveillance scientifique,

- de l'exploitation de la flore et de la faune marines.

2) Suggérer des solutions en vue de résoudre les problèmes divers liés :

- à la sauvegarde de l'Environnement (pollution des eaux marines, protection et aménagement du littoral)

- à la mise en valeur ou aux développements productifs des ressources.

3) Favoriser la concertation entre les organismes et établissements dont les activités sont orientées vers la mer ou les produits marins : les administrations, les collectivités, les laboratoires de recherches et de contrôle, les industriels, les professionnels de la pêche ou de l'exploitation...

4) Participer à l'information objective par des publications, des conférences, des réunions ou tout autre mode de diffusion.

\section{SON ROLE ET SES MOYENS}

De par sa constitution le Centre Français du Littoral n'est pas un établissement de recherches, mais un organe de concertation, de réflexion et de coordination susceptible de proposer des études, d'établir des programmes, de suggérer des solutions.

Ses moyens sont ceux des Laboratoires, des Organismes ou des Entreprises qui participent sous quelque forme que ce soit aux travaux et pour lesquels des crédits peuvent être attribués spécialement.

Il peut également, dans le cadre de conventions bien définies, réaliser la coordination des études, faire exécuter des recherches ou des expérimentations et assurer la gestion des fonds correspondants.

Le Centre Français du Littoral est l'outil de liaison idéal au service d'une commune, d'un département ou d'une région du littoral. Beaucoup l'ont compris, le Centre Français du Littoral est toujours au service des autres.

J.R. CREPEY, président 


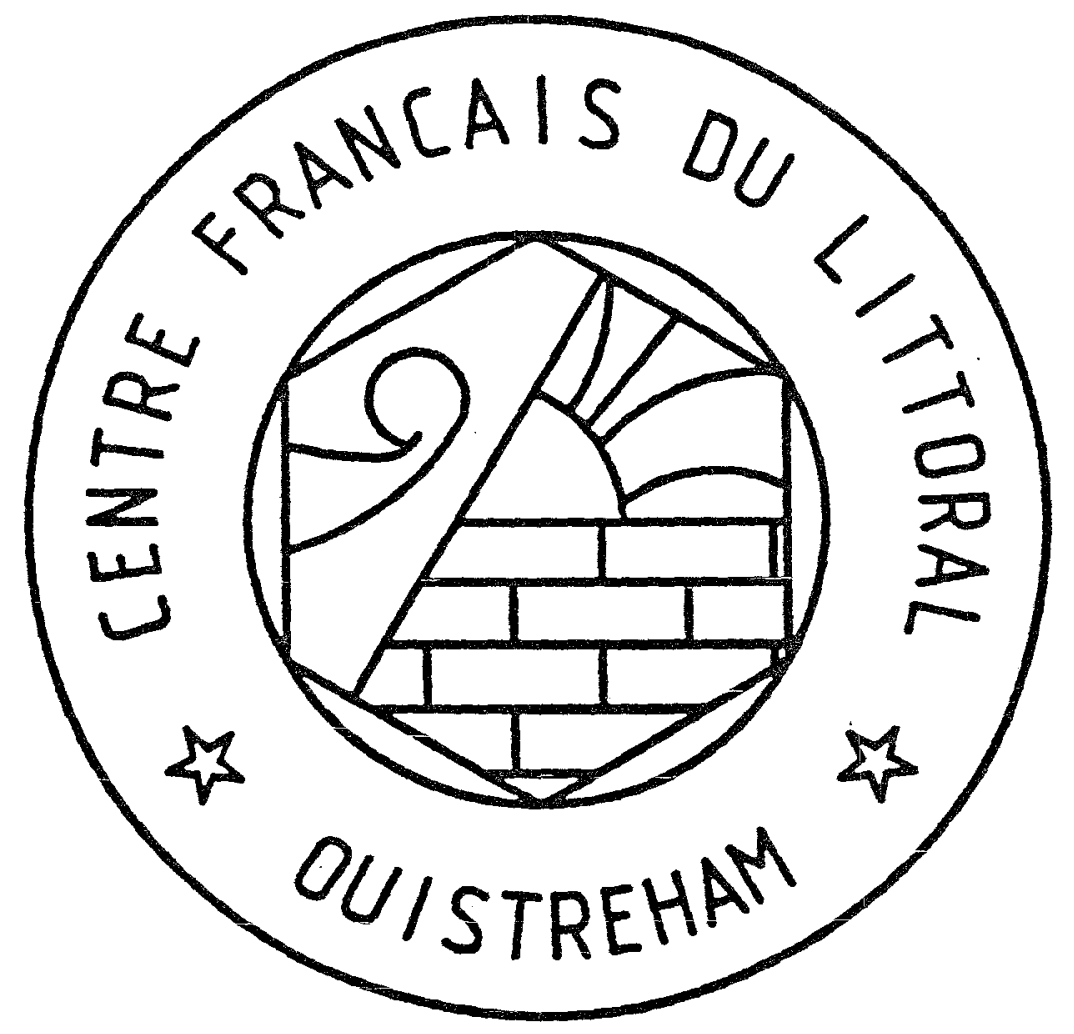

